\title{
Pengaruh Metode Pendidikan al-Qur'an Orang Dewasa terhadap Kemampuan Membaca al-Qur'an
}

\author{
${ }^{1}$ Hafsari , 2 Mardi Takwim, ${ }^{3}$ Nursaeni \\ 1,2,3Program Studi Pendidikan Agama Islam, FTIK, IAIN Palopo \\ E-mail: hafsari.iainpalopo@gmail.com
}

\begin{abstract}
This study aims to determine the method of adult Al-Qur'an education (Dirosa) on the ability to read the Koran. This research is descriptive quantitative research with the ex-post facto design. Determination of the sample is 50\% of the population entitled 90, namely 45 research samples. The research data use questionnaire and test instruments that have been tested for validity and reliability. Before carrying out data analysis, the data were tested first, namely normality test and homogeneity test. Data analysis The results of the study used descriptive statistical analysis and hypothesis analysis. The results showed that: (1) the method of adult Al-Quran education (Dirosa) as a whole respondents who answered always (SL) by 65\%, who answered frequently (SR) by 30\%, who answered sometimes (KD) for 5\%, who answer rarely (JR) and never (TP) by 0\%; (2) Ability to read al-Qur'an respondents with excellent predicate of 43 or $96 \%$, good predicate of 2 or 4\%, predicate sufficient, predicate less and predicate failed at 0 or 0\%; (3) Based on the results of a simple linear regression analysis to determine the effect of adult Al-Qur'an education methods (variable $X$ ) on the ability to read the Qur'an (Variable Y) with the independent variable (method Dirosa) to the honest variable (Qur'anic reading ability is $67.2 \%$, while other variable costs. Significance value is 0,000 <0,05 so HO is rejected and H1 is accepted, which means there is a significant (significant) influence of the Dirosa $(X)$ method variable on the ability to read the Qur'an (Y). The interpretation of the $r$-value of 0.820 shows very strong
\end{abstract}

Keywords: Method of Al-Qur'an Education, Adults, Ability, Reading Al-Qur'an

\begin{abstract}
Abstrak
Penelitian ini bertujuan untuk mengetahui pengaruh metode pendidikan al-Qur'an orang dewasa (dirosa) terhadap kemampuan membaca al-Qur'an. Penelitian ini merupakan penelitian kuantitatif deskriptif dengan desain ex-post facto. Penentuan sampel sebesar 50\% dari populasi yang berjumlah 90 yaitu 45 sampel penelitian. Data penelitian dikumpulkan menggunakan instrumen angket dan tes yang telah melalui uji validitas dan reliabilitas. Sebelum dilakukan analisis data, terlebih dahulu dilakukan uji persyaratan analisis data yaitu uji normalitas dan uji homogenitas. Analisis data hasil penelitian menggunakan analisis statistik deskriptif dan analisis uji hipotesis. Hasil penelitian menunjukkan bahwa: (1) Penerapan metode pendidikan al-Quran orang dewasa (dirosa) secara keseluruhan responden yang menjawab selalu (SL) sebesar 65\%, yang menjawab sering (SR) sebesar 30\%, yang menjawab kadang-kadang (KD) sebesar 5\%, yang menjawab jarang (JR) dan tidak pernah (TP) sebesar 0\%; (2) Kemampuan membaca al-Qur'an responden predikat baik sekali sebesar 43 atau $96 \%$, predikat baik sebesar 2 atau 4\%, predikat cukup, predikat kurang dan predikat gagal sebesar 0 atau 0\%; (3) Berdasarkan hasil analisis regresi linear sederhana untuk mengetahui pengaruh metode pendidikan al-Qur'an orang dewasa (variabel X) terhadap kemampuan membaca al-Qur'an (Variabel Y) bahwa pengaruh variabel bebas (metode dirosa) terhadap variabel terikat (kemampuan membaca al-Qur'an) adalah sebesar $67,2 \%$, sedangkan sisanya dipengaruhi variabel lain. Nilai signifikansi 0,000 < 0,05 maka HO ditolak dan H1 diterima, yang berarti ada
\end{abstract}


pengaruh yang nyata (signifikan) variabel metode dirosa $(X)$ terhadap variabel kemampuan membaca al-Qur'an (Y). Interpretasi nilai $r$ sebesar 0,820 menunjukkan korelasi sangat kuat

Kata Kunci: Metode Pendidikan al-Qur'an, Orang Dewasa, Kemampuan, Membaca al-Qur'an

\section{Pendahuluan}

Kemampuan membaca al-Qur'an merupakan hal yang penting bagi mahasiswa IAIN Palopo sebagai bekal dasar untuk memahami ayat-ayat alQur'an. Mahasiswa yang memiliki tingkat kemampuan membaca yang baik dan benar akan lebih mudah memahami dan mengamalkan isi al-Qur'an. Selain itu, sebagai bekal lulusan dari sebuah perguruan tinggi yang berbasis Agama agar dapat mengamalkan isi al-Qur'an secara utuh.

Allah subhanahu wata'ala telah menjelaskan tentang kewajiban membaca dalam al-Qur'an surah al-Alaq/96:1-5

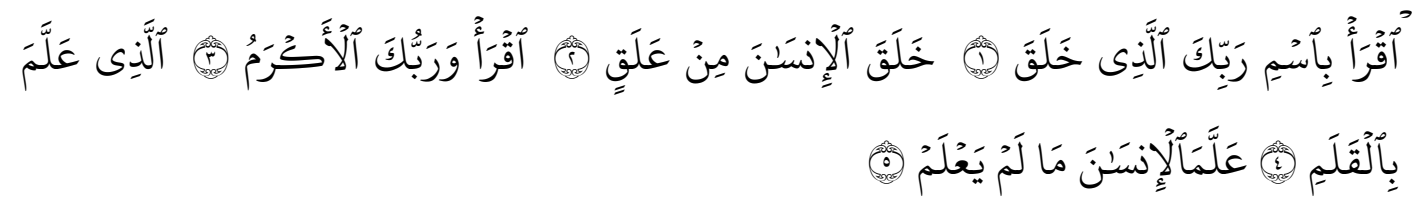

Terjemahnya:

1. Bacalah dengan (menyebut) nama Tuhanmu yang Menciptakan,

2. Dia telah menciptakan manusia dari segumpal darah.

3. Bacalah, dan Tuhanmulah yang Maha pemurah,

4. yang mengajar (manusia) dengan perantaran kalam,

5. Dia mengajar kepada manusia apa yang tidak diketahuinya. ${ }^{1}$

Mahasiswa pada jenjang perguruan tinggi diharapkan sudah mampu membaca al-Qur'an dengan lancar. Untuk tingkatan tersebut mahasiswa harus lebih mampu menguasai berbagai aspek ilmu mengenai kaidah dan seluk beluk tentang membaca al-Qur'an dari segi makhorijul huruf, kaidah penulisan, kaidah membaca, sampai tingkatan yang lebih tinggi, yakni menganalisis, memahami, dan mengamalkan isi dari al-Qur'an.

Allah subhanahu wata'ala menjelaskan dalam al-Qur'an surah alBaqarah/2:121

1Departemen Agama RI, Al-Qur'an dan Terjemahannya, (Cipinang Muara: CV. Darus Sunnah, 2002), h. 598. 


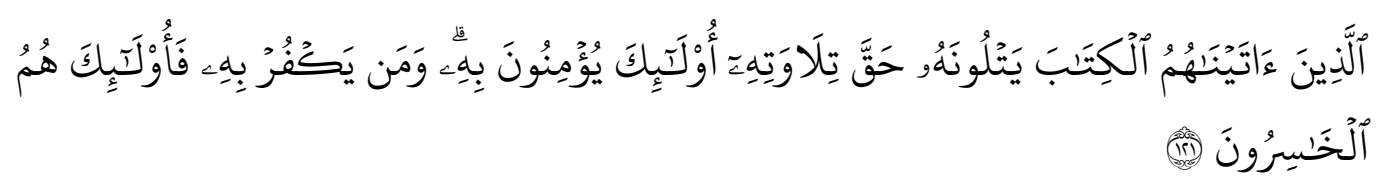

Terjemahnya: Orang-orang yang telah Kami berikan Al kitab kepadanya, mereka membacanya dengan bacaan yang sebenarnya, mereka itu beriman kepadanya. dan Barangsiapa yang ingkar kepadanya, Maka mereka Itulah orang-orang yang rugi. ${ }^{2}$

Dipertegas pula dengan hadits Nabi Muhammad shalallahu 'alaihi wassalam. ${ }^{3}$

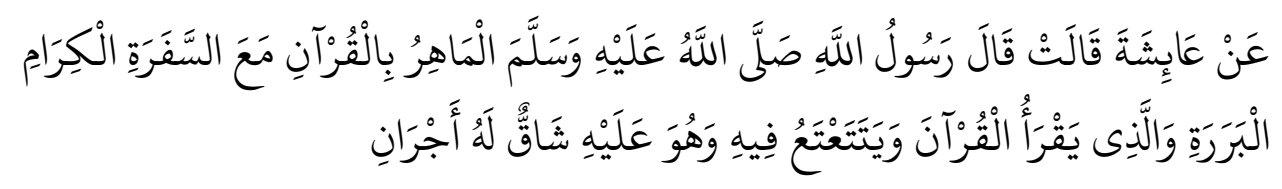

Artinya: Dari 'Aisyah ia berkata; Rasulullah shallallahu 'alaihi wasallam bersabda: "Orang mukmin yang mahir membaca Al Qur`an, maka kedudukannya di akhirat ditemani oleh para malaikat yang mulia. Dan orang yang membaca Al Qur`an dengan gagap, ia sulit dalam membacanya, maka ia mendapat dua pahala." 4

Hadis tersebut merupakan sebuah motivasi betapa penting dan mulianya orang yang selalu membaca al-Qur'an. Orang yang membaca alQur'an dan masih terbata-bata maka baginya dua pahala walaupun masih terasa sulit dalam membacanya. Adapun orang yang mahir dalam membaca alQur'an maka malaikat bersamanya.

Terdapat dua faktor yang perlu menjadi perhatian yakni faktor internal dan faktor ekternal. Faktor internal adalah diri mahasiswa yang menjadi pelaku utama atau subyek pendidikan, dan faktor eksternal yaitu segala sesuatu yang berada di luar diri mahasiswa yang bisa jadi lingkungan dan instrumen lainnya. Untuk mencapai keberhasilan yang diharapkan, tentu tidak terlepas dari berbagai faktor pula yang menunjang keberhasilan tersebut.

2Ibid., h. 20.

${ }^{3} \mathrm{Abu}$ Husain Muslim bin Hajjaj Alqusyairi an Naisaburi, Kitab Shahih Muslim Shalatnya Musafir dan Penjelasan tentang Qashar Juz 1, (Bairut-Libanon: Darul Fikri, 1993), h. 354.

${ }^{4}$ Imam Abi Husein Muslim Ibnu Hajjaj Alqusyairi an Naisaburi, Shahih Muslim Juz I, diterjemahkan oleh Adib Bisri Mustofa dengan Judul Terjamah Shahih Muslim Jilid I, (Semarang: CV Asy-Syifa', 1992), h. 965. 
Faktor yang paling dominan adalah diri mahasiswa. Kemauan yang keras untuk berhasil akan menentukan seberapa jauh tingkat keberhasilan mahasiswa dalam belajar. Indikator keberhasilan mahasiswa dalam pembelajaran adalah mampu dan bisa mengaplikasikan setiap ilmu yang diperolehnya dari pembelajaran tersebut. Kemampuan mengaplikasikan setiap ilmu yang diperoleh dari proses pendidikan dan pembelajaran dalam kehidupan akan melahirkan sebuah kebiasaan positif yang akan mengarahkan pada kehidupan yang lebih baik. Dari berbagai unsur dan faktor-faktor yang dapat diidentifikasikan oleh peneliti maka faktor utama yang menjadi perhatian adalah penggunaan metode untuk diaplikasikan dalam kehidupan sehari-hari. Hal ini merupakan fokus utama yang akan diteliti.

\section{Kerangka Teoretis}

Program pendidikan al-Qur'an orang dewasa (dirosa) adalah pola pembinaan Islam bagi kaum Muslimin pemula (pria, wanita; remaja, orang dewasa, kakek nenek, muallaf) yang dikelola secara sistematis, berjenjang dan berlangsung terus-menerus. ${ }^{5}$ Tujuan program ini dapat terlaksana apabila semua prosesnya dilaksanakan secara berkelanjutan.

Pendidikan al-Qur'an orang dewasa (dirosa) termasuk dalam pembelajaran andragogi. Secara etimologis, andragogi berasal dari bahasa Latin "andros" yang berarti orang dewasa dan "agogos" yang berarti memimpin atau melayani. ${ }^{6}$ Orang dewasa tidak hanya dilihat dari segi biologis semata, tetapi juga dilihat dari segi sosial dan psikologis. Andragogi adalah suatu model proses pembelajaran peserta didik yang terdiri atas orang dewasa. Andragogi disebut juga sebagai teknologi yang melibatkan peserta binaan. ${ }^{7}$ Keterlibatan diri (ego peserta binaan) adalah kunci keberhasilan dalam pembelajaran orang dewasa.

5Wahdah Islamiyah, Belajar Membaca Al-Qur'an dari Nol dengan Metode DIROSA, Situs

Resmi Wahdah. http://wahdah.or.id/belajar-membaca-alquran-dari-nol-dengan-metodedirosa/ (18 Desember 2015).

6 Halim Malik, Teori Belajar Andragogi dan Penerapanny, Situs Resmi Kompasiana.com. http://kompasiana.com (14 Juni 2017).

7 Ibid. 
Pembelajaran al-Qur'an pada era modern ini telah banyak tempattempat pembelajaran al-Qur'an yang tersebar diberbagai pelosok daerah yang menawarkan pendidikan al-Qur'an yaitu sebuah lembaga pendidikan yang menyelenggarakan pendidikan agama khususnya baca tulis al-Qur'an mulai dari tingkat usia anak-anak yang lebih dikenal dengan sebutan TPA (Taman Pendidikan al-Qur'an) hingga usia lanjutan maupun dewasa. Adanya pendidikan-pendidikan tersebut masyrakat kembali sadar akan pentinya belajar al-Qur'an. Selain tempat pendidikan, pengajaran baca tulis al-Qur'an dikembangkan dengan bernagai metode yang intinya untuk memudahkan bagi para pemula memelajari al-Qur'an. Begitu juga buku-buku panduannya telah banyak disusun dan dicetak. Para pengajar baca tulis al-Qur'an tinggal memilih metode paling cocok dan efektif. Hal tersebut yang melatarbelakangi munculnya metode pendidikan al-Qur'an orang dewasa. Namun metode pendidikan al-Qur'an orang dewasa hanya khusus untuk orang dewasa, oleh karena itu metode ini tidak dapat diterapkan pada anak-anak.

a. Tujuh Keunggulan Program Pendidikan al-Qur'an Orang Dewasa (Dirosa)

Setiap program memiliki keunggulan tersendiri, dalam program dirancang khusus untuk orang dewasa, metode yang mudah dan cepat (20 kali pertemuan), biaya pendidikan gratis, waktu dan tempat fleksibel, pembinaan hingga lancar membaca al-Qur'an, bimbingan materi dasar keislaman, serta sangat cocok bagi pemula maupun yang sudah bisa membaca alQur'an.pendidikan al-Qur'an orang dewasa memiliki tujuh keunggulan.8 Adapun keunggulannya yaitu dirancang khusus untuk orang dewasa, metode yang mudah dan cepat (20 kali pertemuan), biaya pendidikan gratis, waktu dan tempat fleksibel, pembinaan hingga lancar membaca al-Qur'an, bimbingan materi dasar keislaman, serta sangat cocok bagi pemula maupun yang sudah bisa membaca al-Qur'an.

b. Tujuan Program Pendidikan al-Qur'an Orang Dewasa (Dirosa) 
Program pendidikan al-Qur'an orang dewasa (dirosa) mempunyai tujuan pencapaian. Program dirosa bertujuan untuk (a) Memberikan kemampuan kepada peserta (remaja dan orang dewasa) agar mampu membaca al-Qur'an dengan baik, lancar dan benar sesuai dengan kaidah ilmu tajwid. (b) Memberikan pengenalan dan pengajaran tentang dasar-dasar keilmuan Islam. ${ }^{9}$

c. Jenis Program

Program pendidikan al-Qur'an orang dewasa memiliki dua jenis program yaitu program klasikal untuk pemula dan program lanjutan ${ }^{10}$ Adapun penjelasannya yaitu sebagai berikut:

1) Program Klasikal Untuk Pemula

Program ini diperuntukkan bagi peserta yang belum bisa membaca $\mathrm{Al}-$ Qur'an (dari nol), atau yang masih terbata-bata, belum benar dalam pengucapan huruf (makhroj) dan panjang-pendeknya serta belum tartil alQur'an. Buku yang digunakan yaitu dirosa ditambah buku pendukung ilmu tajwid.

2) Program Lanjutan

Program ini diperuntukkan bagi peserta yang sudah lancar dalam membaca al-Qur'an tetapi masih terdapat kesalahan bacaan (belum sempurna sesuai dengan kaidah ilmu tajwid). Didukung dengan pembinaan dasar-dasar keislaman serta materi hafalan yang ringan (termasuk doa sehari-hari) sesuai dengan al-Qur'an dan Sunnah. Buku yang digunakan yaitu buku ilmu tajwid, buku akidah Islam, buku ibadah praktis, buku materi hafalan.

d. Target, Alokasi Waktu dan Biaya Program Pendidikan al-Qur'an Orang Dewasa

Program pendidikan al-Qur'an orang dewasa telah memiliki target, pengaturan alokasi waktu serta rincian biaya program. Program ini terbagi atas dua program yaitu program klasikal untuk pemula dan program lanjutan 
yang tertera pada lampiran 13. Program klasikal untuk pemula yang menjadi fokus penelitian menargetkan peserta dirosa mampu mengenal dan mengucapkan makharijul huruf, memahami dan mempraktekkan pelajaran ilmu tajwid dasar serta mampu membaca surah al-Fatihah dengan benar sesuai dengan kaedah ilmu tajwid.

\section{Metode Pendidikan al-Qur'an Orang Dewasa (dirosa)}

Metode berasal dari bahasa Yunani methods yang berarti cara atau jalan yang ditempuh. Sehubungan dengan upaya ilmiah maka metode menyangkut masalah cara kerja untuk dapat memahami objek yang menjadi sasaran ilmu bersangkutan. ${ }^{11}$ Metode pendidikan al-Qur'an orang dewasa (dirosa) ialah pembinaan baca al-Qur'an secara berkelanjutan dengan sistem klasikal 20 kali pertemuan. Panduan baca al-Qur'an pada metode dirosa disusun tahun 2006 yang dikembangkan oleh Wahdah Islamiyah Gowa. Metode pendidikan al-Qur'an orang dewasa dilakukan secara sistematis yang dilengkapi dengan pola-pola tertentu. ${ }^{12}$ Secara garis besar teknik pengajaran metode dirosa adalah baca, tunjuk, simak dan ulang. Adapun secara lengkap mengenai teknik pengajaran membaca al-Qur'an sesuai dengan panduan belajar baca al-Qur'an tertera pada lampiran 14. Dalam panduan belajar baca al-Qur'an sistem klasikal 20 pertemuan pendidikan al-Qur'an orang dewasa (dirosa) diawali dengan bahasan cara melafaskan semua huruf hijaiyah kemudian bahasan selanjutnya mengenai bacaan langsung dan bacaan bersambung dengan urutan penyajian disusun secara sistematis agar peserta binaan lebih aktif dalam belajar membaca al-Qur'an.

Panduan pengajaran metode dirosa terdiri dari 3 tahap yang berlangsung selama 90 menit. ${ }^{13}$ Adapun panduan singkat tentang pelaksanaan metode dirosa yaitu sebagai berikut:

11 Wikipedia Bahasa Indonesia Ensklopedia Bebas, Pengertian Metode, http://www.wikipedia.org, (22 Mei 2017).

12 Komari dan Sunarsih, Panduan Belajar Baca al-Qur'an Sistem Klasikal 20 Pertemuan DIROSA", (Cet. XIX; Lembaga Pembinaan dan Pengembangan Pendidikan al-Qur'an (LP3Q) Dewan Pimpinan Pusat Wahdah Islamiyah, 2013), h. 7.

13 Ibid, h. 8. 
a) Pembukaan selama 5 menit: Doa belajar, absensi serta pengarahan singkat tentang keutamaan belajar dan mengajarkan al-Qur'an serta menjaga kehadiran.

b) Kegiatan inti selama 80 menit

1) Pengulangan singkat materi yang lalu

2) Pembahasan judul materi (pokok bahasan)

3) Pembina menulis materi satu persatu di papan tulis, atau dengan menggunakan peraga kemudian melafaskannya dan ditirukan oleh peserta

4) Teknik 1 (T1) yaitu pemberian contoh. Pembina membacakan materi, peserta menunjuk tulisan

5) Teknik 2 (T2) yaitu menuntun. Pembina membacakan materi, kemudian peserta menirukan, jika bacaan peserta belum kompak, pembina mengulangi bacaannya kemudian ditirukan oleh semua peserta

6) Teknik 3 (T3) yaitu baca bersama. Pembina dan semua peserta membaca bersama-sama

7) Baca Simak (BS) yaitu satu persatu dari semua peserta bergiliran membaca satu baris. Ketika dibaca, peserta yang lain menirukan. Pembina menyimak dengan seksama, membenarkan yang salah serta menandai bagian yang belum dikuasai peserta

8) Teknik 2 (T2)

9) Teknik 3 (T3)

10)Baca Simak (BS)

11)Membaca berpasangan yaitu dua peserta saling berhadapan, satu orang membaca satu halaman, pasangannya menyimak dan membenarkan jika ada kesalahan. Jika mereka tidak menguasai, ditanyakan kepada pembina

12)Membaca mandiri= tiap peserta membaca sendiri satu halaman

c) Penutup

1) Apresiasi hasil belajar 
2) Saran, usul, dan kritikan

3) Infak

4) Problem solving, evaluasi serta do'a penutup

2. Kemampuan Membaca al-Qur'an

Gambar 2.1 Kemampuan Membaca al-Qur'an

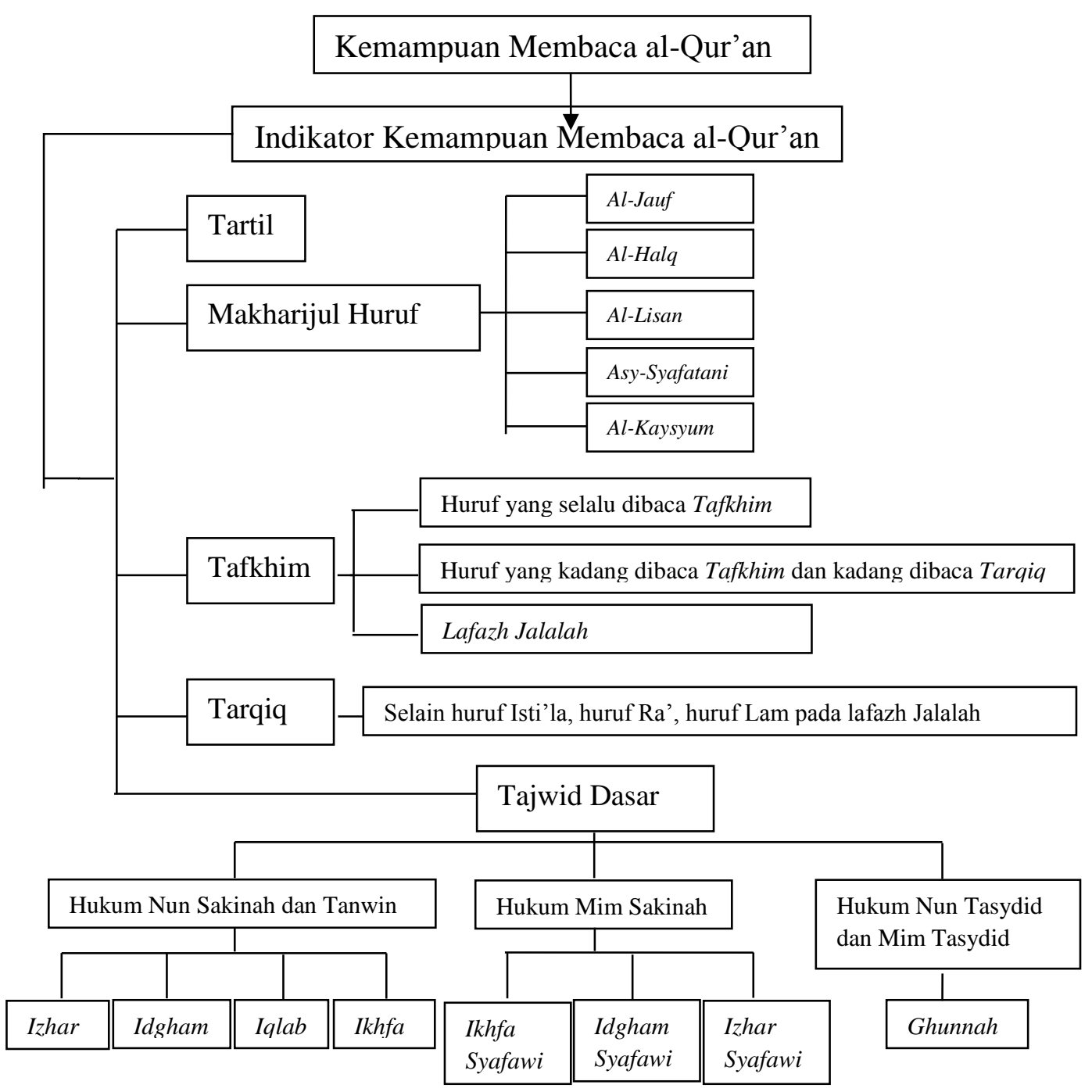

Kegiatan membaca menjadi suatu hal yang sangat penting dalam alQur'an, sehingga ayat pertama kali yang diturunkan dalam sejarah turunya alQur'an adalah perintah membaca yang tertuang dalam Q.S. al-Alaq/96:1. 
Kaitannya dengan membaca al-Qur'an, maka perlu suatu penjelasan singkat terkait dengan hal tersebut sehingga apa yang belum jelas ataupun yang belum diketahui dapat dikaji lebih mendalam.

a. Pengertian Kemampuan Membaca al-Qur'an

Kamus besar bahasa Indonesia WJS. Poerwadarminto, kemampuan memiliki kata dasar mampu yang berarti kuasa (sanggup melakukan sesuatu). Jadi kemampuan memiliki arti kesanggupan, kecakapan, kekuatan. ${ }^{14}$ Sedangkan membaca memiliki arti melihat tulisan dan mengerti atau dapat melisankan apa yang tertulis itu. ${ }^{15}$ Membaca merupakan salah satu aktivitas belajar. Hakikat membaca adalah suatu proses yang kompleks dan rumit karena dipengaruhi oleh faktor internal dan eksternal yang bertujuan untuk memahami arti atau makna yang ada di dalam tulisan tersebut.

Wahyu yang pertama yang disampaikan kepada nabi Muhammad shallallahu 'alaihi wasallam adalah perintah membaca karena dengan membaca Allah subhanahu wata'ala mengajarkan tentang suatu pengetahuan yang tidak diketahuinya. Dengan membaca manusia akan mendapatkan wawasan tentang suatu ilmu pengetahuan yang akan berguna bagi dirinya kelak.

Ditinjau dari segi kebahasaan, ada beberapa pendapat yang mengartikan al-Qur'an antara lain:

Menurut pendapat para qurro, kata "Qur'an" berasal dari kata "qorooin" yang berarti "qorina”. Maksudnya ayat-ayat al-Qur'an yang satu dengan yang lainnya saling membenarkan. ${ }^{16}$ Dan menurut pendapat yang termasyhur kata "Qur'an" berasal dari kata "qoroa" yang berarti bacaan. ${ }^{17}$ Pengertian ini diambil berdasarkan ayat al-Qur'an Q.S. al-Qiyamah/75: 17-18

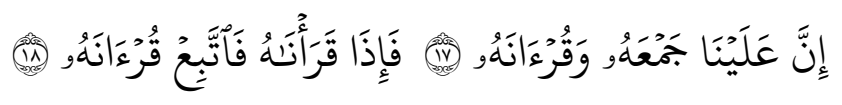

${ }^{14}$ WJS. Poerwaedarminto, Kamus Umum Bahasa Indonesia, (Jakarta: Balai Pustaka, 1987), h. 628.

15 Ibid. h.71.

16 Moh. Chaddziq Charisma, Tiga Aspek Kemukjizatan al-Qur'an, (Surabaya: PT Bina Ilmu, 1991), h. 1.

${ }^{17}$ Ibid. 
Terjemahnya:

17. Sesungguhnya atas tanggungan kamilah mengumpulkannya (di dadamu) dan (membuatmu pandai) membacanya.

18. apabila Kami telah selesai membacakannya Maka ikutilah bacaannya itu. 18

Pengertian al-Qur'an menurut istilah antara lain yaitu al-Qur'an artinya kitab suci agama Islam berisi kumpulan firman Allah subhanahu wata'ala yang diwahyukan kepada Nabi Muhammad shalallahu 'alaihi wasallam melalui perantara malaikat Jibril. ${ }^{19}$ Arti lain dari al-Qur'anul Karim adalah kalam Allah subhanahu wata'ala yang diturunkan kepada Rasulullah shalallahu 'alaihi wasallam termasuk ibadah bagi orang yang membacanya, dibatasi oleh beberapa surah, orang yang memindahkan bacaannya kepada kita merupakan pemindahan bacaan yang mutawatir (bersambung sanadnya sampai Rasulullah shalallahu 'alaihi wasallam). ${ }^{20}$

Pengertian lain, al-Qur'an adalah kalam Allah subhanahu wata'ala yang tiada tandingannya (mukjizat), diturunkan kepada Nabi Muhammad shalallahu 'alaihi wasallam penutup para Nabi dan Rasul dengan perantaraan Malikat Jibril . Dimulai dengan surah al-Fatihah dan diakhiri surah an-Nash, dan ditulis dalam mushaf-mushaf yang disampaikan kepada kita secara mutawatir (oleh orang banyak), serta memelajarinya merupakan suatu ibadah. $^{21}$ Jadi pengertian tersebut yang dimaksud peneliti, kemampuan membaca al-Qur'an adalah suatu kemampuan dalam membaca al-Qur'an dengan baik dan benar sesuai kaidah ilmu tajwid.

18 Departemen Agama RI, Al-Qur'an dan Terjemahannya, (Cipinang Muara: CV. Darus Sunnah, 2002), h. 578.

19 Badan Pengembangan dan Pembinaan Bahasa Kementrian Pendidikan Kebudayaan, Kamus Bahasa Indonesia untuk Pelajar, (Cet.I; 2011), h. 16.

20 Otong Surahman, Metode Insan Kunci Praktis Membaca al-Qur'an baik dan benar, (Cet. II; Jakarta: Gema Insani Press, 2002), h. 15.

21 Muhammad Ali Ash-Shabuni, At-Tibyaan Fii Uluumil Quran, diterjemahkan oleh Aminuddin dengan judul Studi Ilmu al-Qur'an, (Bandung: CV Pustaka Setia, 1999), h. 15. 
b. Indikator Kemampuan Membaca al-Qur'an pada Program Dirosa

Berdasarkan target sistem klasikal pada program dirosa, maka yang termasuk dalam indikator kemampuan membaca al-Qur'an yang dimaksud yaitu sebagai berikut:

1) Tartil

Kata tartil berasal dari bahasa arab yaitu تَرْبِّلاً yang berarti perlahan-lahan. Pengertian tartil dalam membaca al-Qur'an yaitu membaguskan bacaan hurufhuruf al-Qur'an dengan terang, terartur dan tidak terburu-buru serta mengenai tempat-tempat waqaf sesuai aturan-aturan tajwid. ${ }^{22}$

2) Makharij al-Huruf (Tempat-tempat Keluarnya Huruf)

a) Pengertian Makharij al-Huruf

Makharij al-huruf adalah tempat-tempat keluarnya bunyi huruf, yaitu tempat bunyinya suara keluar dari rongga mulut akibat adanya tekanan udara pada selaput suara. Bunyi suara apabila dikeluarkan dari sumber yang berlainan dalam rongga mulut akan menghasilkan bunyi suara yang berlainan pula. Bunyi suara yang keluar dari salah satu sumber itulah yang dikenal dengan istilah huruf. ${ }^{23}$

b) Pembagian Makharij al-Huruf

Makharijul Huruf terbagi atas 17 makhraj yang dikelompokkan ke

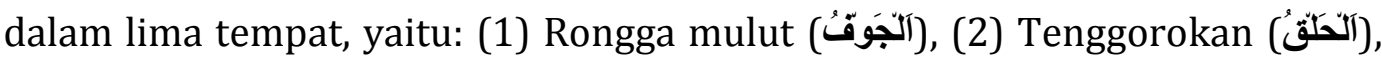

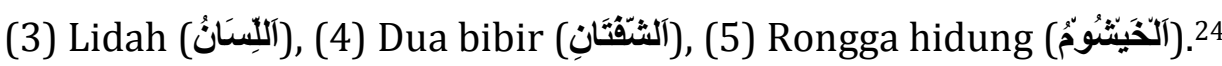

Berikut pembagian Makharijul Huruf secara terperinci:

${ }^{22}$ Fauziah, Peningkatan Kemampuan Membaca al-Qur'an Secara Tartil Sesuai dengan Ilmu Tajwid Bagi Siswa Kelas IV MI al-Islam Lesanpuro Kecamatan Kajoran Kabupaten Magelang, (Skripsi STAIN Salatiga, 2011), h. 19.

${ }^{23}$ Lembaga Muslimah Wahdah Islamiyah, Panduan Ilmu Tajwid, (Cet. IV; Makassar: BP3Q LM DPP WI, 2014) ,h.31.

${ }^{20}$ Ibid., h. 32. 
(1) Al-Jauf (ألَجَوقتُ (rongga mulut), yaitu kelompok makhraj huruf yang ada di rongga mulut. Hurufnya adalah alif( (1) sebelumnya berbaris fathah, ya (ي ) sebelumnya berbaris kasrah dan waw (و (و sebelumnya berbaris dhammah. Ketiga huruf tersebut berfungsi sebagai mad ashli.

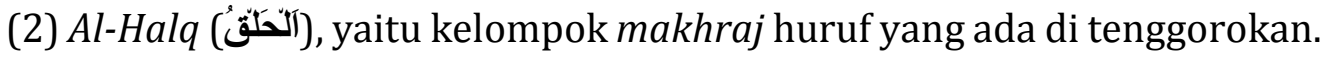
Terdiri dari 6 huruf yang terbagi menjadi tiga makhraj, yaitu:

(a) Tenggorokan Bawah: Hurufnya: $\&$ -

(b) Tenggorokan Tengah: Hurufnya: $\varepsilon-\tau$

(c) Tenggorokan Atas : Hurufnya: $\dot{\varepsilon}-\dot{\tau}$

(3) Al-Lisan (اللّسََانُ)/ lidah, yaitu kelompok makhraj huruf yang ada di lidah. Terdiri atas 18 huruf yang terbagi ke dalam10 makhra, yakni sebagai berikut:

(a) Pangkal lidah (dekat tenggorokan) bertemu dengan langit-langit (anak tekak), hurufnya yaitu:

(b) Pangkal lidah diturunkan agak kedepan, hurufnya yaitu:

(c) Pertengahan lidah bertemu dengan langit-langit.hurufnya yaitu: - ش - ش

(d) Salah satu tepi (sisi) lidah atau keduanya bertemu dengan gigi geraham atas. Hurufnya: ض

(e) Salah satu sisi lidah yang dekat ke ujungnya bertemu dengan langit-langit yang sejajar dengannya. Hurufnya yaitu: $J$

(f) Tepi ujung lidah bertemu dengan gusi depan atas, suara menekan ke langitlangit sampai ke rongga hidung. Hurufnya yaitu: ن

(g) Ujung lidah bagian luar bertemu dengan gusi depan atas yang sejajar dengannya, suara agak bergetar. Hurufnya: $\lrcorner$

(h) Ujung atas lidah bertemu dengan pangkal gigi depan (seri) atas. Hurufnya yaitu:

(i) Ujung atas lidah bertemu dengan rongga antara gigi atas dengan gigi bawah (lebih dekat ke bawah). Hurufnya yaitu: ص - س - ص

(j) Ujung lidah bertemu dengan ujung gigi depan (seri) atas. Hurufnya: - ذ ظ

(k) Asy-Syafatani (آلثَّقَتَّنان) yaitu kelompok makhraj yang ada di bibir. Terdiri 4 huruf yang terbagi menjadi dua makhraj, yaitu: 
$\checkmark$ Perut bibir bawah bertemu dengan ujung gigi depan (seri) atas. Hurufnya: ف

$\checkmark$ Antara dua bibir. Hurufnya:

Catatan: Huruf ب dilafalkan dengan mempertemukan dua bibir sambilmerapatkan dan menekan sedikit, karena adanya sifat syiddah (kuat) yang dimiliki huruf ini. Huruf p dilafalkan dengan mempertemukan duabibir sambilmerapatkan dan tidak menekan. Huruf $و$ dilafalkan dengan memonyongkan kedua bibir, termasuk dalam makhraj ini huruf slayyin (huruf waw sukun yang huruf sebelumnya berbaris fathah.


hidung. Rongga hidung sebenarnya bukan tempat keluarnya bunyi huruf, tetapi karena Ilmu Tajwid mempelajari huruf dalam berbagai hubungannya, maka rongga hidung dikelompokkan sebagai makhraj huruf yang mengeluarkan bunyi suara dengung. Hurufnya adalah sebagai berikut:

$\checkmark$ huruf Nun (ن) ketika bertasydid (musyaddadah)

$\checkmark \operatorname{huruf} \operatorname{Mim}($ ) ketika bertasydid (musyaddadah)

$\checkmark$ huruf Nun Sukun dan tanwinketika idgham bighunnah,ikhfa'haqiqih, dan Iqlab

$\checkmark$ huruf Mim Sukun ketikaidgham syafawi dan ikhfa' syafawi

$\checkmark$ huruf Ba (ب) ketika bertemu Mim (idgham mutajanisan)

Catatan: Perlu hati-hati pada penyebutan wawu (و) bertasydid untuk tidak membacanya dengan dengung.

Latihan untuk pelafalan huruf dan untuk mengetahui makhraj suatu huruf, para ulama menganjurkan agar huruf tersebut ditasydidkan dan disukunkan, kemudian didahului dengan huruf hidup. Ketika suara bertahan, maka tampaklah makhraj dari huruf yang bersangkutan.

Contoh:

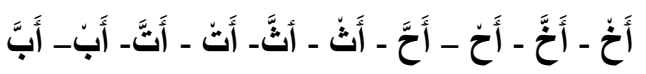

3) Tafkhim dan Tarqiq

Tafkhim berarti menebalkan suara huruf sedangkan tarqiq berarti menipiskan suara huruf. Dalam membaca al-Qur'an, pemahaman tentang 
tafkhim dan tarqiq sangat diperlukan, karena hal ini termasuk bagian dari kesempurnaan tilawah (bacaan). ${ }^{25}$

Tafkhim dan tarqiq (tebal dan tipisnya huruf), huruf hijaiyah dikelompokkan menjadi tiga, yaitu:

a) Huruf yang selalu dibaca tafkhim

Huruf yang selalu dibaca tafkhim adalah semua huruf isti'la'. Huruf isti'la' adalah huruf hijaiyah yang ketika diucapkan lidah terangkat ke langitlangit. Huruf isti'la' terdiri atas tujuh huruf, yaitu:

$$
\text { ص - ض - ط- }
$$

$\checkmark$ Tingkatan tafkhim yang kuat, yaitu ketika huruf-huruf tafkhim tersebut berharakat fathah atau dhammah,dan ketika sukun dan sebelumnya berharakat fathah atau dhommah.

$\checkmark$ Tingkatan tafkhim yang ringan, yaitu ketika huruf-huruf tafkhim tersebut berharakat kasrah atau ketika sukun dan sebelumnya terdapat huruf berharakat kasrah.

b) Huruf yang kadang dibaca Tafkhim dan kadang dibaca Tarqiq

(1) Huruf $R a^{\prime}$

Huruf $R a^{\prime}$ dibaca Tafkhim (tebal) apabila:

$\checkmark$ Berharakat fathah baik di awal, di tengah atau diakhir kata dalam keadaan washal/disambung.

$\checkmark$ Berharakat dhommah,baik di awal, di tengah, atau diakhir kata dalam keadaan washal.

$\checkmark$ Huruf Ra' sukun dan didahului huruf berharakat fathah baik di tengah atau di akhir kata atau bila huruf Ra' sukun sebelumnya terdapat huruf sukun yang didahului huruf berharakat fathah.

$\checkmark$ Huruf Ra'sukun dan didahului huruf berharakat dhammah baik di tengah atau di akhir kata, atau bila huruf Ra' sukun dan sebelumnya terdapat huruf sukun yang didahului huruf berharakat dhammah.

25 Ibid.,h. 53. 
$\checkmark \quad$ Huruf $R a^{\prime}$ sukun dan sebelumnya terdapat huruf berharakat kasrah asli dalam keadaan terpisah (dua kata).

$\checkmark$ Huruf Ra' sukun dan didahului oleh huruf berharakat kasrah tidak asli dalam keadaan bersambung (satu kata).

$\checkmark$ Huruf Ra' sukun dan didahului oleh huruf berharakat kasrah asli dan setelahnya terdapat huruf isti'la' berharakat fathah dalam satu kata, dan keadaan ini hanya terdapat pada 5 kata dalam al-Qur'an (khilaf di kalangan ulama namun ini saja dituliskan).

$\checkmark$ Huruf Ra' dibaca tarqiq (tipis) apabila:

$\checkmark$ Berharakat kasrah baik di awal, di tengah, atau di akhir kata dalam keadaan washal.

$\checkmark$ Huruf Ra' sukun dan didahului huruf berharakat kasrah, baik di tengah atau di akhir kata, atau bila huruf Ra' sukun dan sebelumnya terdapat huruf sukun yang didahului huruf berharakat kasrah.

$\checkmark \quad$ Huruf Ra' sukun yang didahului oleh huruf yang berharakat kasrah asli dan sesudahnya tidak terdapat huruf isti'la' atau terdapat huruf isti'la'namun dalam dua kata.

$\checkmark \quad$ Huruf $R a^{\prime}$ sukun dan didahului oleh huruf $y a^{\prime}$ mad atau ya'lin.

\section{(2) Lafazh Jalalah (الله)}

$\checkmark$ Huruf Lam (J) pada lafazh الله dibaca tafkhim (tebal) jika didahului huruf yang berharakat fathah atau dhammah.

$\checkmark$ Huruf Lam (J) pada lafazh الله dibaca tarqiq (tipis) jika didahului huruf yang berharakat kasrah.

(3) Alif Mad (huruf Alif berfungsi sebagai mad)

$\checkmark$ Alif Mad dibaca tafkhim (tebal) jika didahului huruf yang tebal.

$\checkmark$ Alif Mad dibaca tarqiq (tipis) jika didahului huruf yang tipis.

c) Huruf yang selalu dibaca Tarqiq

Huruf hijaiyah selain huruf isti'la', huruf $R a^{\prime}(J)$, huruf Lam (J) pada lafazh Jalalah dan Alif Mad, maka semuanya dibaca Tarqiq (tipis). 
4) Tajwid Dasar

(a) Hukum Nun Sakinah (نे) dan Tanwin

Nun sakinah berarti Nun yang tidak berharakat berada pada kata benda, kata kerja, dan huruf serta berada pada tengah dan akhir kata. Sedangkan tanwin secara etimologi berarti penyuaraan. Tanwin hanya berada pada kata benda dan selalu berada pada akhir kata. ${ }^{26}$ Hukum nun sakinah dan tanwin terbagi atas beberapa hukum, yaitu sebagai berikut:

(1) Izh-Har

Secara etimologi artinya jelas dan terang. Secara terminologi mengeluarkan huruf nun sakinah dan tanwin dari makhrajnya dengan jelas dan tidak berdengung jika bertemu dengan huruf-huruf izh-har. Izh-har juga berarti memisahkan antara huruf yang pertama (nun sakinah) dengan huruf yang kedua (huruf-huruf izh-har) dengan tidak berhenti padanya (tidak mengambil nafas). Huruf-huruf izh-har meliputi huruf-huruf yang keluar dari tenggorokan, yakni huruf: $\bullet-\bullet-\varepsilon-\dot{\varepsilon}-\dot{\tau}$. Sebab Terjadinya izh-har adalah karena jauhnya makhraj nun sakiah dari makhraj huruf-huruf izh-har. Disebut izh-har halqy karena huruf-huruf izh-har keluar dari tenggorokan.

(2) Idgham

Pengertian secara etimologi idgham berarti memasukkan. Secara terminology, Idgham berarti bertemunya nun sakinah atau tanwin dengan huruf yang berharakat (salah satu huruf idgham) dimana kedua huruf trsebut menjadi satu (lebur) dan bertasydid. Huruf-huruf Idgham ada enam, yaitu: نو : Pembagian hukum Idgham ada dua yaitu idgham bhigunnah

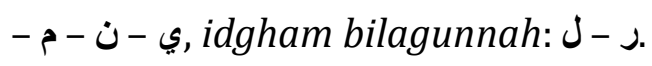

(3) Iqlab

Iqlab secara etimologi berarti merubah. Sedangkan secara terminologi, Iqlab berarti menempatkan satu huruf pada tempat yang lain, atau merubah nun sakinah atau tanwin ketika bertemu dengan huruf $b a^{\prime}$ menjadi mim dan 
disertai ghunnah. Huruf Iqlab hanya satu, yaitu $b a^{\prime}$ ( ب) . Pelafalan suara mim terdengar sempurna dan kedua bibir merapat dengan ditekan.

(4) Ikhfa'

Secara etimologi, ikhfa' berarti tersembunyi. Sedangkan secara terminology, ikhfa' berarti penyebutan huruf yang bersukun (nun sakinah atau tanwin) tanpa tasydid dengan sifat antara izh-har dan idgham, tanpa menghilangkan sifat ghunnah yang ada pada huruf tersebut (nun sakinah atau tanwin). Huruf $i k h f a^{\prime}$ ada 15, yaitu:

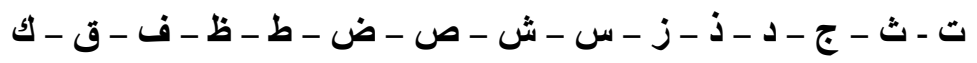

(b) Hukum Mim Sakinah ( $\vec{p}$ )

Mim Sakinah adalah mim yang tidak berharakat, sukunnya tetap baik ketika washal (disambung) maupun waqaf (berhenti), terletak di tengah atau di akhir kata benda, kata kerja dan huruf. ${ }^{27}$ Hukum mim sakinah terbagi atas 3, yaitu:

(1) Ikhfa' Syafawi, yaitu apabila mim sakinah bertemu dengan huruf $b a^{\prime}$, dinamakan syafahian karena huruf mim dan $b a^{\prime}$ mempunyai makhraj yang sama yaitu dari kedua bibir.

(2) Idgham Syafawi, yaitu apabila mim sakinah bertemu dengan huruf mim yang berharakat.

(3) Izh-har Syafawi, yaitu apabila mim sakinah bertemu dengan semua huruf hijaiyah kecuali huruf mim dan ba'.

(c) Hukum Nun dan Mim Tasydid

Setiap Nun dan Mim yang bertasydid maka hukumnya adalah ghunnah (wajib didengungkan) sepanjang dua harakat, baik bacaan tersebut disambung (washal) atau berhenti (waqaf), di tengah atau di akhir kata. ${ }^{28}$ Adapun mengenai ukuran ghunnah, sebagian ulama qira'ah menetapkan dengan cara menutup jari atau membukanya dengan gerakan yang tidak terlalu cepat dan tidak pula terlalu lambat.

27 Ibid., h. 75

28 Ibid., h. 81. 


\section{Metode dan Hasil Penelitian}

Penelitian ini menggunakan penelitian kuantitatif deskriptif, yaitu penelitian yang melihat pengaruh metode dirosa terhadap kemampuan membaca al-Qur'an. Peneliti memilih salah satu lembaga kemahasiswaan ekstrakurikuler yang aktif dalam bidang keagamaan di IAIN Palopo yaitu Forum Mahasiswa Al-Hikmah (FMH) IAIN Palopo. Sekretariat Forum Mahasiswa al-Hikmah IAIN Palopo beralamatkan di Jl. Cempaka, Kelurahan Balandai, Kecamatan Bara. Berdasarkan data yang didapatkan peneliti dari Forum Mahasiswa al-Hikmah IAIN Palopo bahwa jumlah keseluruhan peserta binaan yaitu 90 orang. Jadi jumlah populasi dalam penelitian ini yaitu sebanyak 90. peneliti dalam menentukan jumlah sampel mengambil 50\% dari jumlah populasi yaitu sebanyak 45 sampel.

Data primer adalah data empirik yang diperoleh langsung dari responden. Sedangkan data sekunder adalah data yang diperoleh melalui sumber bacaan ilmiah atau literatur yang ada kaitannya dengan obyek penelitian seperti buku yang ditulis oleh Komari dan Sunarsih dengan judul "Panduan Belajar Baca al-Qur'an", buku yang dibuat oleh Lembaga Wahdah Islamiyah dengan judul "Panduan Ilmu Tajwid I", dan literatur lainnya.

1) Hasil Analisis Statistik Deskriptif Metode Dirosa (Variabel $X$ )

Peneliti melakukan analisis statistik deskriptif terhadap hasil penelitian angket responden tentang pelaksanaan metode dirosa yang diperoleh data sebagai berikut:

Tabel 4.4 Analisis Statistik Deskriptif Angket

Statistics
AngketMetodeDirosa
\begin{tabular}{|l|r|}
\hline \multicolumn{1}{|c|}{ Valid } & Missing \\
Mean & 45 \\
Median & 0 \\
Mode & 64.33 \\
Std. Deviation & 66.00 \\
Range & 67 \\
Minimum & 3.580 \\
Maximum & 14 \\
Sum & 55 \\
\end{tabular}


Gambar 4.1 Hasil Persentase Item

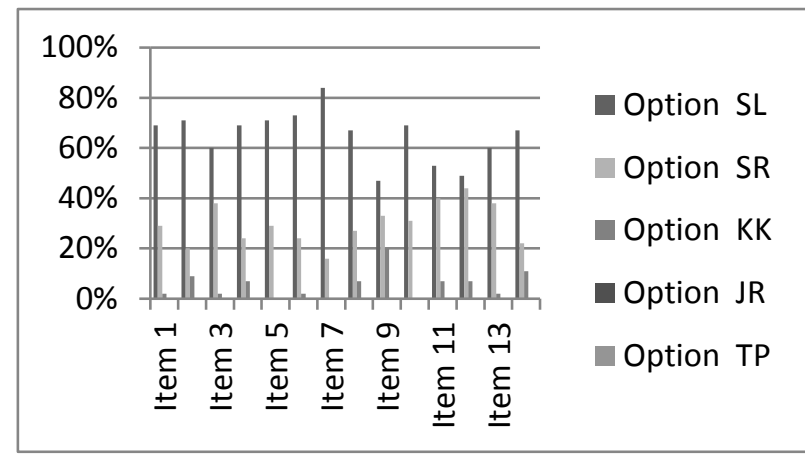

Hasil tersebut dapat disimpulkan bahwa pelaksanaan metode pendidikan al-Quran orang dewasa telah diterapkan pada Forum Mahasiswa al-Hikmah IAIN Palopo.

2) Hasil Analisis Statistik Deskriptif Kemampuan Membaca al-Qur'an (Variabel Y)

Analisis deskriptif pada hasil tes lisan responden mengenai kemampuan membaca al-Qur'an diperoleh sebagai berikut

Tabel 4.5 Analisis Statistik Deskriptif Hasil Tes Kemampuan Membaca al-Qur'an

Vtatistics
\begin{tabular}{|l|r|}
\hline VAR00001 & Valid \\
Mean & Missing \\
Median & 0 \\
Mode & 91.39 \\
Std. Deviation & 91.67 \\
Variance & 94 \\
Range & 5.153 \\
Minimum & 26.555 \\
Maximum & 21 \\
Sum & 77 \\
\hline
\end{tabular}

Kemampuan membaca al-Qur'an responden predikat baik sekali sebesar 43 atau $96 \%$, predikat baik sebesar 2 atau 4\%, predikat cukup sebesar 0 atau $0 \%$, predikat kurang sebesar 0 atau $0 \%$, dan predikat gagal sebesar 0 atau $0 \%$. 
a) Analisis Regresi Linear Sederhana

Hasil olah data dengan menggunakan program IBM Statistic Version 23 yaitu pada tabel berikut:

Tabel 4.8 Output Pertama (Variabel Entered/Removed) Analisis Regresi Linear Sederhana

\begin{tabular}{|l|l|l|l|}
\hline \multicolumn{4}{|c|}{ Variables Entered/Removed $^{\mathrm{a}}$} \\
Model & $\begin{array}{c}\text { Variables } \\
\text { Entered }\end{array}$ & $\begin{array}{c}\text { Variables } \\
\text { Removed }\end{array}$ & \multicolumn{1}{|c|}{ Method } \\
\hline 1 & MetodeDirosa & & Enter \\
\hline
\end{tabular}

a. Dependent Variable: KemampuanMembacaAlQuran

b. All requested variables entered.

Tabel 4.9 Output Kedua (Model Summary) Analisis Regresi Linear Sederhana

\begin{tabular}{|l|r|r|r|r|}
\hline \multicolumn{1}{|c|}{ Model Summary } \\
\hline Model & $\mathrm{R}$ & R Square & \multicolumn{1}{c|}{$\begin{array}{c}\text { Adjusted R } \\
\text { Square }\end{array}$} & $\begin{array}{c}\text { Std. Error of the } \\
\text { Estimate }\end{array}$ \\
\hline 1 & $.820^{\mathrm{a}}$ & .672 & .665 & 3.018 \\
\hline
\end{tabular}

a. Predictors: (Constant), MetodeDirosa

Tabel 4.10 Output Ketiga (Anova) Analisis Regresi Linear Sederhana

\begin{tabular}{|ll|r|r|r|r|r|}
\hline \multicolumn{1}{|c|}{ Model $^{2}$} & Sum of Squares & Df & Mean Square & F & Sig. \\
\hline 1 & Regression & 803.066 & 1 & 803.066 & 88.151 & $.000^{\mathrm{b}}$ \\
& Residual & 391.734 & 43 & 9.110 & & \\
& Total & 1194.800 & 44 & & & \\
\hline
\end{tabular}

a. Dependent Variable: KemampuanMembacaAlQuran

b. Predictors: (Constant), MetodeDirosa

Tabel 4.11 Output Keempat (Coefficient) Analisis Regresi Linear Sederhana

\begin{tabular}{|c|c|c|c|c|c|c|}
\hline \multicolumn{7}{|c|}{ Coefficients ${ }^{\mathbf{a}}$} \\
\hline \multirow{2}{*}{\multicolumn{2}{|c|}{ Model }} & \multicolumn{2}{|c|}{ Unstandardized Coefficients } & \multirow{2}{*}{$\begin{array}{c}\begin{array}{c}\text { Standardized } \\
\text { Coefficients }\end{array} \\
\text { Beta } \\
\end{array}$} & \multirow[b]{2}{*}{$\mathrm{t}$} & \multirow[b]{2}{*}{ Sig. } \\
\hline & & $\mathrm{B}$ & Std. Error & & & \\
\hline \multirow[t]{2}{*}{1} & (Constant) & 14.833 & 8.189 & & 1.811 & .077 \\
\hline & MetodeDirosa & 1.193 & .127 & .820 & 9.389 & .000 \\
\hline
\end{tabular}

a. Dependent Variable: KemampuanMembacaAlQuran 
Tabel coefficients dalam kolom B pada Constant (a) adalah 14,833 , sedangkan nilai metode dirosa (b) adalah 1,193, sehingga persamaan regresinya dapat ditulis:

$$
\hat{\mathrm{Y}}=\mathrm{a}+\mathrm{bX} \text { atau } \hat{\mathrm{Y}}=14,833+1,193 \mathrm{X}
$$

Koefisien b dinamakan koefisisen arah regresi dan menyatakan perubahan rata-rata variabel $Y$ untuk setiap perubahan variabel X sebesar satu satuan. Perubahan ini merupakan pertambahan bila $b$ bertanda positif dan penurunan bila b bertanda negatif. Sehingga dari persamaan tersebut dapat diterjemahkan : Konstanta sebesar 14,833 menyatakan bahwa jika tidak ada nilai metode dirosa maka nilai kemampuan membaca al-Qur'an sebesar 14,833. Koefisien regresi $\mathrm{X}$ sebesar 1,193 menyatakan bahwa setiap penambahan 1 nilai metode dirosa, maka nilai kemampuan membaca alQur'an bertambah sebesar 1,193.

Dari output dapat diketahui nilai t hitung=9,389 dengan nilai signifikansi $0,000<0,05$ maka $\mathrm{H}_{0}$ ditolak dan $\mathrm{H}_{1}$ diterima, yang berarti ada pengaruh yang nyata (signifikan) variabel metode dirosa (X) terhadap variabel kemampuan membaca al-Qur'an (Y).

b) Analisis Korelasi Regresi Linear Sederhana

Tabel 4.12 Hasil Analisis Korelasi Regresi Linear Sederhana

\begin{tabular}{|ll|r|r|}
\hline \multicolumn{1}{|c|}{ Correlations } & & $\begin{array}{c}\text { Kemampuan } \\
\text { Membaca } \\
\text { AlQuran }\end{array}$ \\
\hline MetodeDirosa & Pearson Correlation & Metode Dirosa & $.820^{* *}$ \\
& Sig. (2-tailed) & 1 & .000 \\
& $\mathrm{~N}$ & 45 & 45 \\
\hline KemampuanMembacaAlQura & Pearson Correlation & $.820^{* *}$ & 1 \\
$\mathrm{n}$ & Sig. (2-tailed) & .000 & 45 \\
& $\mathrm{~N}$ & 45 & 45 \\
\end{tabular}

\footnotetext{
**. Correlation is significant at the 0.01 level (2-tailed).
} 


$$
\begin{aligned}
\mathrm{KP} & =r^{2} \times 100 \% \\
& =0,820^{2} \times 100 \% \\
& =0,6724 \times 100 \% \\
& =67,24 \%
\end{aligned}
$$

Artinya pengaruh metode pendidikan al-Qur'an orang dewasa terhadap kemampuan membaca al-Qur'an pada Forum Mahasiswa al-Hikmah IAIN Palopo sebesar 67,24\% dengan 32,76\% ditentukan oleh variabel lain. Variabel lainnya yang mempengaruhi kemampuan membaca al-Qur'an dapat berupa faktor internal maupun eksternal.

\section{Penutup}

Berdasarkan hasil analisis data dan pembahasan hasil penelitian yang telah dikemukakan maka dapat disimpulkan sebagai berikut:

1. Pelaksanaan metode pendidikan al-Quran orang dewasa telah diterapkan pada Forum Mahasiswa al-Hikmah IAIN Palopo. Metode tersebut telah dilaksanakan sesuai dengan teknik panduan program pendidikan alQur'an orang dewasa.

2. Kemampuan membaca al-Qur'an pada Forum Mahasiswa al-Hikmah cukup beragam seperti responden predikat baik sekali sebesar 43 atau 96 $\%$, predikat baik sebesar 2 atau 4\%, predikat cukup sebesar 0 atau $0 \%$, predikat kurang sebesar 0 atau $0 \%$, dan predikat gagal sebesar 0 atau $0 \%$.

3. Berdasarkan hasil analisis regresi linear sederhana ada pengaruh yang nyata (signifikan) variabel metode dirosa $(\mathrm{X})$ terhadap variabel kemampuan membaca al-Qur'an (Y). Interpretasi tingkat korelasi dari hasil analisis korelasi regresi linear sederhana menghasilkan koefisien korelasi nilai r sebesar 0,820 menunjukkan korelasi sangat kuat.

\section{Daftar Pustaka}


Ash-Shabuni, Muhammad Ali, At-Tibyaan Fii Uluumil Quran, diterjemahkan oleh Aminuddin dengan judul Studi Ilmu al-Qur'an. Bandung: CV Pustaka Setia, 1999.

Badan Pengembangan dan Pembinaan Bahasa Kementrian Pendidikan Kebudayaan, Kamus Bahasa Indonesia untuk Pelajar, Cet.I; 2011.

Departemen Agama RI, Al-Qur'an dan Terjemahannya, Cipinang Muara: CV. Darus Sunnah. 2002.

Fauziah, Peningkatan Kemampuan Membaca al-Qur'an Secara Tartil Sesuai dengan Ilmu Tajwid Bagi Siswa Kelas IV MI al-Islam Lesanpuro Kecamatan Kajoran Kabupaten Magelang. Skripsi. STAIN Salatiga, 2011

Islamiyah, Wahdah, Belajar Membaca Al-Qur'an dari Nol dengan Metode DIROSA, Situs Resmi Wahdah. http://wahdah.or.id/belajar-membacaalquran-dari-nol-dengan-metode-dirosa/ (18 Desember 2015).

Komari dan Sunarsih, Panduan Belajar Baca al-Qur'an Sistem Klasikal 20 Pertemuan DIROSA", (Cet. XIX; Lembaga Pembinaan dan Pengembangan Pendidikan al-Qur'an (LP3Q) Dewan Pimpinan Pusat Wahdah Islamiyah, 2013.

Malik, Halim. Teori Belajar Andragogi dan Penerapanny, Situs Resmi Kompasiana.com. http://kompasiana.com (14 Juni 2017).

Moh. Chaddziq Charisma, Tiga Aspek Kemukjizatan al-Qur'an. Surabaya: PT Bina Ilmu, 1991.

Naisaburi, Abu Husain Muslim bin Hajjaj Alqusyairi an. Kitab Shahih Muslim Shalatnya Musafir dan Penjelasan tentang Qashar Juz 1. Bairut-Libanon: Darul Fikri, 1993.

Naisaburi, Imam Abi Husein Muslim Ibnu Hajjaj Alqusyairi an, Shahih Muslim Juz I , diterjemahkan oleh Adib Bisri Mustofa dengan Judul Terjamah Shahih Muslim Jilid I. Semarang: CV Asy-Syifa', 1992.

Poerwaedarminto, Kamus Umum Bahasa Indonesia. Jakarta: Balai Pustaka, 1987.

Surahman ,Otong, Metode Insan Kunci Praktis Membaca al-Qur'an baik dan benar. Cet. II; Jakarta: Gema Insani Press, 2002.

Wikipedia Bahasa Indonesia Ensklopedia Bebas, Pengertian Metode, http://www.wikipedia.org, (22 Mei 2017). 